\title{
Ditadura militar e repressão de gênero: o uso e o abuso do corpo feminimo
}

\author{
Military dictatorship and gender repression: the use and abuse of the feminine body \\ Dictadura militar y represión de género: el uso y abuso del cuerpo femenino
}

Recebido: 09/12/2021 | Revisado: 14/12/2021 | Aceito: 25/12/2021 | Publicado: 05/01/2022

\author{
Hugo Pires Júnior \\ ORCID: https://orcid.org/0000-0002-8840-1065 \\ Universidade Estadual do Sudoeste da Bahia, Brasil \\ E-mail: hugohugone@hotmail.com \\ Lívia Diana Rocha Magalhães \\ ORCID: https://orcid.org/0000-0003-0784-6749 \\ Universidade Estadual do Sudoeste da Bahia, Brasil \\ E-mail: 1rochamagalhaes@gmail.com
}

\begin{abstract}
Resumo
No presente texto discutimos que a tortura contra mulheres militantes e presas durante a ditadura militar no Brasil (1964-1985) tem sobretudo especificidades de gênero. Nos depoimentos das cindo mulheres militantes que estudamos, a partir de seus relatos na Comissão Nacional e Comissões Regionais da Verdade, fica evidente que crimes brutais de caráter sexual e de gênero, de uso e abuso do corpo feminino, se tornaram uma prática legitimada e institucionalizada pelo governo militar. Uma constatação que também tem ocorrido em outros estudos acerca de contextos ditatoriais, apesar de ainda ser uma abordagem a ser mais pesquisada. Destarte, os depoimentos também demonstram que essas mulheres continuam zelando por suas memórias e trajetórias políticas. A tortura, a violência de gênero ainda estão presentes em suas memórias, mas não as intimidaram ou as impediram de colocar em cena a alteridade de gênero e suas memórias individuais-coletivas a serviço da verdade e da justiça.
\end{abstract}

Palavras-chave: Ditadura militar; Mulheres; Tortura; Gênero; Abuso; Corpo feminino.

\begin{abstract}
In this text, we discuss that torture against militant women and prisoners during the military dictatorship in Brazil (1964-1985) has above all gender specificities. In the testimonies of the five women activists we studied, based on their reports in the National Commission and Regional Truth Commissions, it is evident that brutal crimes of a sexual and gender nature, of use and abuse of the female body, have become a legitimate and institutionalized practice. by the military government. A finding that has also occurred in other studies about dictatorial contexts, despite still being an approach to be further researched. Thus, the testimonies also demonstrate that these women continue to care for their memories and political trajectories. Torture and gender violence are still present in their memories, but they did not intimidate or prevent them from putting gender alterity and their individual-collective memories in the service of truth and justice.
\end{abstract}

Keywords: Military dictatorship; Women; Torture; Gender; Abuse; Feminine body.

\begin{abstract}
Resumen
En este texto discutimos que la tortura contra mujeres militantes y prisioneras durante la dictadura militar en Brasil (1964-1985) tiene sobre todo especificidades de género. En los testimonios de las cinco mujeres activistas estudiadas, con base en sus informes en la Comisión Nacional y Comisiones Regionales de la Verdad, se evidencia que los crímenes brutales de carácter sexual y de género, de uso y abuso del cuerpo femenino, se han convertido en un legítimo y práctica institucionalizada por el gobierno militar. Un hallazgo que también se ha dado en otros estudios sobre contextos dictatoriales, a pesar de que todavía es un enfoque por investigar. Así, los testimonios también demuestran que estas mujeres continúan velando por sus recuerdos y trayectorias políticas. La tortura y la violencia de género siguen presentes en su memoria, pero no las intimidaron ni les impidieron retratar la alteridad de género y sus memorias individual-colectivas al servicio de la verdad y la justicia.
\end{abstract}

Palabras clave: Dictadura militar; Mujer; Tortura; Género; Abuso; Cuerpo femenino.

\section{Introdução}

Neste texto, apresentamos indicativos dos resultados da pesquisa realizada acerca das torturas sofridas por mulheres militantes, no final dos anos de 1960, a partir da promulgação do Ato Institucional número cinco (AI-5) em dezembro de 1968, período em que a ditadura militar, no Brasil, passa a atuar de forma brutal contra todas as organizações de esquerda. A ditadura recrudesce a violência, tolhendo as liberdades individuais e coletivas erigida sob os princípios da Doutrina da 
Segurança Nacional e Desenvolvimento (DSND), como lembra Alves (1989) e Dreifuss (1981). As organizações de esquerda passam a ser proibidas levando um número significativo de jovens, a maioria estudantes, a viverem na ilegalidade. E, como "fora-da-lei" são caçados, sequestrados, torturados, mortos ou desaparecem sumariamente. O arbítrio é estabelecido, as denúncias e delações transformam-se em práticas comuns sendo materializadas as ações contrárias aos direitos humanos, as liberdades individuais e coletivas. Os sequestros, sem prisões oficiais, liberam os órgãos de repressão a produzirem ações repressivas contundentes. E, é nesse contexto, que se inclui o nosso estudo sobre a trajetória de mulheres militantes, que sofreram torturas de gênero do ponto de vista simbólico e material.

\section{Metodologia}

Trata-se de uma pesquisa de caráter histórico-documental que visa compreender pelo menos duas dimensões dialéticas da realidade sócio-política em estudo, ou seja, "información referencial fáctica sobre acontecimientos, procesos, situaciones" como também "interpretaciones del entrevistado, las significaciones que construye, los sentidos que le otorga a la propia experiencia, sus valores y creencias" (Vega, 2009, p. 01). Recorremos, para a realização da pesquisa, às narrativas de cinco mulheres militantes: Romeu (2016); Ramminger (2016); Cardoso (2016); Murat (2016) e Chaves (2016), perseguidas, presas e torturadas durante a ditadura militar no Brasil (1964-1985) e que relataram as torturas sofridas nas audiências públicas promovidas pela Comissão Nacional da Verdade (CNV), instaurada no ano de 2012 em cumprimento da Lei $\mathrm{n}^{\circ} 12.528$ promulgada em 18 de novembro de 2011, e pelas Comissões Regionais da Verdade (CRV). Documentos que fazem parte dos acervos da CNV (DF), CRV (RS), CRV (RJ) e OAB (RJ) e estão disponíveis para domínio público.

Realiza-se um esforço de pesquisa, como enfatiza Colling (1997), direcionado a demonstrar, entre outros aspectos, a participação política da mulher e os efeitos que foram produzidos a partir das análises de gênero. E como é anunciado por essa autora (1997), ocorre a "abertura para novos objetos na história" (p.10), em que as relações de gênero passam a ocupar amplos espaços e trazem a discussão sobre a mulher em suas várias instâncias de atuação política. Dentre outros podemos destacar estudos pioneiros como aqueles realizados por Colin (1997); Sarti (1998); Ridenti (1990/2016); Souza (2012); Rosa (2013); Salgado (2013); Gianordoli-Nascimento (2012); Trindade \& Santos (2012) e Grossi (2016) que continuam contribuindo para "explicar como as mulheres tornam-se sujeitos" (p. 14) de si mesmas e protagonistas de sua posição nas lutas políticas contemporâneas, particularmente durante os chamados "anos de chumbo" (1968-1974). O interesse acadêmico pelo tema vem ampliando-se e incorporando discussões conceituais e históricas, do ponto de vista da relação poliédrica entre um dado campo conhecimento e a memória social e coletiva. Por exemplo, podemos destacar entre estudos mais recentes, as pesquisas de Lima (2019), Oliveira (2020), Cavalcanti Júnior (2020)i, Vecchi e Di Eugenio (2020), Zacchi (2009), dentre outros.

\section{Resultados e Discussão}

Nas últimas décadas do século XX e nos anos do século em curso, vem aparecendo uma importante discussão reflexiva sobre os estudos da repressão política, o da memória de gênero. A plasticidade demonstrada pelo campo da memória confere-lhe estrutura multidisciplinar que é reveladora de toda sua força e lhe empresta amplos saberes que circulam ao redor de seus objetos em constante construção, pois demonstram suas relações com campos diferenciados do conhecimento e estabelecem interfaces com objetos de estudos interdisciplinares, revelando, como diria Farias (2010), seu caráter "multimodal".

Nessa perspectiva, dentre outros referenciais teóricos, recorremos as contribuições de Halbwachs (2004), principalmente quando teoriza que a nossa memória se ampara em quadros sociais, em experiências vividas, sob dadas circunstâncias, se edifica na relação individual-coletiva e se reconstrói com os dados obtidos até o presente.

No estudo que realizamos, todas as narrativas das cinco mulheres vítimas da repressão durante a ditadura militar no 
Brasil (1964-1985) estão claramente acompanhadas de um forte relato sobre a violência sexual. Nas denúncias realizadas por essas mulheres militantes, comparecem a recordação de uma memória vivida e reelaborada com detalhes acerca do perfil e, muitas vezes, os nomes dos torturadores e tipos de torturas executadas. Repressão adotada por militares, que transformaram as prisioneiras em objetos de agressões morais e físicas a qualquer horário e dia. Os choques elétricos nos seios, genitálias e em outras partes do corpo, palavras de baixo calão, gritos e agressividade, sadismos, pancadas violentas, estupros constantes, compõem os relatos dessas mulheres. Como, também, outras torturas psicológicas relacionadas a perseguições e ameaças a suas famílias, prole e companheiros. Uma delas, relembra o nascimento de sua filha na prisão e os insultos por ser mulher, mãe e ter se atrevido a atuar na vida pública, na militância política. O depoimento dessas mulheres que denunciam as suas duras experiências, as mais íntimas, deixam patentes que os crimes de violência sexual e de gênero foram utilizados de forma contundente durante a ditadura militar, evidenciando a violência de gênero numa situação bastante clara, de hierarquias e relações de poder (Scott, 1990).

$\mathrm{E}$, assim, diríamos que as pesquisas que situam a ditatura no Brasil ainda precisam ser mais estudadas à luz dos quadros sociais e das experiências de gênero ou, como ressalta Jelin (2002), é preciso considerar que a "repressão tem gênero", ou seja, que as [...] ditaduras do Cone Sul tiveram especificidades de gênero, fato óbvio e explicável por suas posições diferenciadas no sistema de gênero, pois que implicam experiências vitais e relações sociais hierárquicas claramente distintas (p.100). E também é necessário destacar que "todos os informes existentes sobre a tortura indicam que o corpo feminino foi um objeto "especial" para os torturadores (2002, p. 102).

\section{Conclusão}

A trajetória das mulheres perseguidas e torturadas politicamente, assim como outros estudos no e fora do Brasil, revelam que ainda temos muito a pesquisar sobre as questões de gênero em regimes repressores, servindo de parâmetro para intimidar e torturar mulheres, como também a homens à luz da dominação de gênero. É fundamental que esses relatos sejam conhecidos, socializados em espaços educativos de toda natureza e colocados na ordem do dia, que haja uma militância que persiste por meio o protagonismo de gênero de mulheres que recuperam memórias individuais-coletivas a serviço da busca da dignidade, da verdade, da justiça contra o uso e abuso da violência de gênero utilizadas durante a ditadura militar no Brasil. Continuamos ressaltando, que de certo modo, ainda são parcos os estudos sobre a mulher engajada politicamente, por isso, ainda há muito a ser revelado sobre uma sociedade androcêntrica que a todo custo tenta suprimir as mulheres da história e dizimar as memórias sociais e políticas de suas ações e das violências de gênero por elas sofridas.

\section{Referências}

Alves, M. H. M. (1981). Estado e oposição no Brasil (1964-1984). 2. ed. Petrópolis: Vozes.

Cardoso, A. N. (2016). Relatos de sobrevivência: Nilce Azevedo Cardoso. Obtido via internet, https://resistenciaemarquivo.wordpress.com/2014/08/15/relatode-sobrevivencia-nilce-azevedo-cardoso/comment-page-1/.

Cavalcanti Junior, A. A. (2020) As Dinas do Araguaia: diferentes trajetórias de uma luta contra a Ditadura Militar. Tese (Doutorado em História). Programa de Pós-Graduação em História - Universidade Federal da Grande Dourados (UFGD).

Chaves, E. L. (2016). Depoimento de Eliana Lorentz Chaves à Comissão da Verdade do Rio de Janeiro. Obtido via internet, http://atarde.uol.com.br/politica/noticias/-depoimento-de-eliana-lorenz-chaves-a-comissao-da-verdade-do-rio.

Colling, A. M. (1997). A resistência da mulher à ditadura militar no Brasil. Rio de Janeiro: Record/Rosa dos Tempos.

Dreifuss, R A. (1981). 1964: A conquista do Estado - Ação política, poder e golpe de classe. 5. Ed. Petrópolis, Vozes.

Farias, E. S. de. (2010). Teoria da memória: a memória como problema filosófico e científico. Vitoria da Conquista: Universidade Estadual do Sudoeste da Baia (UESB).

Gianordoli-Nascimento, I. F., Trindade, Z. A., Santos, M. de F. de S. (2012). Mulheres e militância: encontros e confrontos durante a ditadura militar. Belo Horizonte: UFMG. 
Grossi, M. P. (2016). Identidade de gênero e sexualidade. http://bibliobase.sermais.pt:8008/BiblioNET/upload/PDF3/01935_identidade_genero_revisado.pdf.

Halbwachs, M. (2004). A memória coletiva. São Paulo: Centauro.

Jelin, E. (2016). Los trabajos de la memoria. España: Siglo Veintiuno, 2001. Capítulo 6. El género en las memorias. Obtido via internet, http://www.cholonautas.edu.pe/modulo/upload/JelinCap6.pdf.

Lima, G. de O. P. (2019). Do corpo insepulto à luta por memória, verdade e justiça: um estudo do caso Dinaelza Coqueiro. Tese (Doutorado) - Programa de Pós-Graduação em Memória: Linguagem e Sociedade - PPGMLS. Universidade Estadual do Sudoeste da Bahia.

Murat, L. (2013). Depoimento de Lúcia Murat à Comissão da Verdade do Rio de Janeiro. Obtido via internet, http://atarde.uol.com.br/politica/noticias/1506981-depoimento-de-lucia-murat-a-comissao-da-verdade-do-rio, 28/05/2013, 18h39m atualizado em 28/05/2013, $19 \mathrm{~h} 24 \mathrm{~m}, 2016$.

Oliveira, M. C. S. de (2020). O feminismo acadêmico do jornal Mulherio na construção de uma memória contra o androcentrismo, Dissertação (Mestrado) Universidade Estadual do Sudoeste da Bahia, Programa de Pós-graduação em Memória: Linguagem e Sociedade-PPGMLS, Vitória da Conquista.

Ramminger, I. M. S. (2016). Martinha: “ainda não vivemos uma democracia plena”. Obtido via internet, http://www.sul21.com.br/jornal/martinha-ainda-naovivemos-uma-democracia-plena/, 16/dez/2013, 8h11m.

Romeu, I. E. (2016). Tortura praticada pela polícia civil. Ordem dos Advogados do Brasil. Conselho Federal - Comissão de Direito Humanos - Processo ${ }^{\circ}$ F-CDH-017/80. Relatório. Obtido via internet, http://www.epsjv.fiocruz.br/upload/doc/DEPOIMENTO_INES.pdf.

Salgado, L. de B. (2013). Sofrimento, gênero política. Anais Eletrônicos. X Seminário Internacional Fazendo Gênero, Florianópolis. Obtido via internet, http://www.fazendogenero.ufsc.br/10/resources/anais/20/1386610602_ARQUIVO_LiviadeBarrosSalgado.pdf.

Sarti, C. (1998). O início do feminismo sob a ditadura no Brasil: o que ficou escondido, 1998. Em: Anais do XXI Congresso Internacional da LASA, Chicago, 24-26 de setembro.

Scott, J. (2010) Gender: a useful category of historical analyses. Gender and the politics of history. New York: Columbia University Press. 1990. Traduzido por Christine Rufino Dabat e Maria Betânia Ávila e autorizada à divulgação com autorização da autora. Obtido via internet. https://disciplinas.stoa.usp.br/pluginfile.php/185058/mod_resource/content/2/G\%C3\%AAnero-Joan\%20Scott.pdf.

Souza, L. de. (2012). Prefácio. In: Gianordoli-Nascimento, I. F., Trindade, Z. A., Santos, M. de F. de S. Mulheres e militância: encontros e confrontos durante a ditadura militar. Belo Horizonte: UFMG, p. 13-22.

Vecchi, R., \& Di Eugenio, A. . (2020). A dupla cicatriz: a ditadura brasileira e a vocalização feminina da memória traumática de Ana Maria Machado. Estudos De Literatura Brasileira Contemporânea, (60), 1-10. https://doi.org/10.1590/2316-4018609.

Veja, N. "La entrevista como fuente de información: orientaciones para su utilización", em Luciano Alonso y Adriana Falchini, eds., Memoria e Historia del Pasado Reciente. Problemas didácticos y disciplinares, Santa Fe, Universidad Nacional del Litoral, en prensa 2009.

Zacchi, L. L. (2009). Violências de gênero nas memórias traumáticas de mulheres sobre a ditadura civil-militar brasileira. Trabalho de Conclusão de Curso (TCC) Universidade Federal de Santa Catarina. Orientadora: Janine Gomes da Silva.

i Pesquisas realizadas no Grupo de Pesquisa "Educação, Memória e História da Bahia: processos autoritários e ditadura militar", no Museu Pedagógico, da Universidade Estadual do Sudoeste da Bahia (UESB) no qual a presente pesquisa se insere. 